\title{
Perinatal mortality in different ethnic groups
}

\author{
L S CHITTY AND R M WINTER
}

Kennedy-Galton Centre for Clinical Genetics, Northwick Park Hospital, Harrow, Middlesex

SUMMARY We have analysed the cause of perinatal deaths in four hospitals in the North West Thames region over a six year period commencing January 1980. The Pakistani population had a significantly greater perinatal mortality rate $(15 \cdot 7 / 1000$ births) than the Europeans $(11 \cdot 3 / 1000$ births). This was due to an increased incidence of macerated stillbirths and lethal malformations, the latter resulting from a significantly higher incidence of autosomal recessive disorders, neural tube defects, and renal malformations.

Several studies have shown that there is a higher perinatal mortality rate in the Asian subgroup of the British population. ${ }^{1-3}$ This has been attributed to a higher incidence of stillbirths of low birth weight and in deaths due to congenital malformations. ${ }^{34}$ It has been suggested that greater maternal age, higher parity, lower social class, and a high incidence of consanguineous marriage in the Asian population are aetiological factors in the higher perinatal mortality rate. ${ }^{12}$ The aims of this study were to assess the contribution of lethal congenital malformations to perinatal mortality in different ethnic groups, to investigate the incidence of definite and probable autosomal recessive syndromes, and to estimate the possible effect of consanguinity.

\section{Patients and methods}

The population studied included all babies born from January 1980 until the end of December 1985 at four hospitals in the North West Thames region. These hospitals were selected because they notified births by ethnic group, which enabled accurate definition of ethnic perinatal mortality rates. The groups studied were Europeans, Pakistanis, and Asians from India. Other groups notified included Asians from Africa and Bangladesh, Chinese, Arabs, Africans, and Vietnamese, but these have not been further subdivided as numbers were too small to permit meaningful analysis.

Perinatal deaths were identified by inspection of the labour ward registers of births (to ascertain all stillbirths) and the neonatal intensive care registers, which recorded all neonatal deaths and transfers to other units. Where babies had been transferred to units not included in the study information regard- ing their outcome was sought from the receiving hospital. Where possible ascertainment of perinatal deaths was checked against other sources of information such as necropsy files and perinatal mortality meeting records. Maternal and neonatal case records were examined to determine the circumstances of death, necropsy details, karyotype, maternal ethnic group, religion, consanguinity, age, parity, and medical, obstetric, and family history. The genetic case records were examined in cases that had been referred for genetic opinion. Deaths were then classified by cause or mode of death as described by Wigglesworth. ${ }^{5}$ This permits classification based on simplified pathological subgroupings to which most perinatal deaths can be provisionally assigned even if necropsy is not done and provides groups with implications for aetiology (table 1). Statistical analysis was performed using Fisher's exact two tailed test and confidence intervals were calculated as described by Morris and Gardner. ${ }^{6}$

\section{Results}

There were 63442 births in the six year period: 50164 Europeans (79.0\%), 3507 Pakistanis (5.5\%), 3367 Indian Asians $(5 \cdot 3 \%)$, and 6404 others $(10 \cdot 2 \%)$. There was a total of 803 perinatal deaths giving an overall perinatal mortality rate of $12.6 /$ 1000 births. The distribution of deaths between the different pathological subgroups is shown in table 1 . Four of the babies classified as macerated stillbirths had minor malformations not thought severe enough to cause death. These were mild bilateral hydronephrosis, a small ventricular septal defect, an isolated cleft palate, and a small meningocoele. In $13(1.6 \%)$ cases it was not possible to classify the 
Table 1 Perinatal deaths in different ethnic groups (per 1000 births)

\begin{tabular}{|c|c|c|c|c|}
\hline Pathological subgroup & European & Pakistani & Indian & Total $^{*}(\%)$ \\
\hline Macerated stillbirths & $142(2 \cdot 8)$ & $17(4 \cdot 8) \dagger$ & $10(3 \cdot 0)$ & $200(24.9)$ \\
\hline Congenital malformations & $151(3 \cdot 0)$ & $24(6 \cdot 8) \dagger$ & $11(3 \cdot 3)$ & $209(26 \cdot 0)$ \\
\hline $\begin{array}{l}\text { Conditions associated } \\
\text { with immaturity }\end{array}$ & $141(2 \cdot 8)$ & $7(2 \cdot 0)$ & $13(3 \cdot 9)$ & $204(25 \cdot 4)$ \\
\hline $\begin{array}{l}\text { Conditions associated } \\
\text { with birth asphyxia }\end{array}$ & $110(2 \cdot 2)$ & $5(1.4)$ & $8(2 \cdot 4)$ & $147(18 \cdot 3)$ \\
\hline Other $\ddagger$ & $21(0.4)$ & $2(0 \cdot 6)$ & $1(0 \cdot 3)$ & $30(3 \cdot 8)$ \\
\hline Unclassified & - & - & - & $13(1 \cdot 6)$ \\
\hline Total & 565 & 55 & 43 & 803 \\
\hline $\begin{array}{l}\text { Perinatal mortality } \\
\text { rate } / 1000 \text { births }\end{array}$ & $11 \cdot 3$ & $15 \cdot 7 \dagger$ & $12 \cdot 8$ & $12 \cdot 6$ \\
\hline
\end{tabular}

${ }^{*}$ Includes perinatal deaths from all ethnic groups.

†Compared with Europeans p $<0.05$.

$\ddagger$ Rhesus disease, non-immune hydrops, metabolic disorders, etc.

deaths because the notes were unobtainable and insufficient information was available from the labour ward and neonatal registers. A total of 543 $(67.6 \%)$ babies had undergone postmortem examination.

PERINATAL MORTALITY BY ETHNIC GROUP

The Pakistanis had a significantly higher perinatal mortality rate $(15 \cdot 7 / 1000$ births) than the Europeans $(11 \cdot 3 / 1000$ births) (odds ratio $1 \cdot 39,95 \%$ confidence interval 1.05 to $1.82, \mathrm{p}<0.05)$. The Indian rate $(12 \cdot 8 / 1000$ births) was not significantly different from that of either of the other groups.

ETHNIC DIFFERENCES IN PATHOLOGICAL SUBGROUP There was no significant difference between groups in deaths due to immaturity, birth asphyxial conditions, and other specific causes (table 1). The increased perinatal mortality rate in Pakistanis when compared with Europeans was entirely accounted for by significantly higher incidences of macerated stillbirths (odds ratio $1 \cdot 67,95 \%$ confidence interval 1.02 to $2.78, \mathrm{p}<0.05$ ) and lethal congenital malformations (odds ratio $2.33,95 \%$ confidence interval 1.49 to $3.57, \mathrm{p}<0.01$ ). The Indians had slightly higher rates than Europeans in all categories but these did not reach significance.

\section{ANALYSIS OF LETHAL MALFORMATIONS}

During the period of the study 209 babies died as a result of congenital malformations. Postmortem examination had been performed in 150 cases and successful chromosome analysis in 52 cases. Seventy two of these babies were stillborn and 137 died in the neonatal period as a result of their malformations. Table 2 shows the incidence of malformations by system subdivided into ethnic groups. There were significantly higher incidences of neural tube

Table 2 Malformations divided by system in different ethnic groups and the potential for prenatal detection ${ }^{7}$

\begin{tabular}{|c|c|c|c|c|}
\hline & \multicolumn{3}{|c|}{ No in study (incidence/1000 births) } & \multirow{2}{*}{$\begin{array}{l}\text { No }(\%) \text { detectable by } \\
\text { prenatal ultrasound }\end{array}$} \\
\hline & European & Pakistani & Indian & \\
\hline Central nervous system & $3(0.06)$ & $2(0 \cdot 57)$ & 0 & $1(20)$ \\
\hline Neural tube defects & $37(0.73)$ & $7(1.99)^{*}$ & $2(0.59)$ & $46(100)$ \\
\hline Cardiovascular & $24(0.48)$ & $2(0.57)$ & $2(0.59)$ & $12(43)$ \\
\hline Renal & $16(0.32)$ & $5(1.43)^{* *}$ & $2(0.59)$ & $12(52)$ \\
\hline Gastrointestinal & $4(0.08)$ & 0 & $1(0 \cdot 29)$ & $4(80)$ \\
\hline Musculoskeletal & $12(0.24)$ & 0 & $1(0 \cdot 29)$ & $5(38)$ \\
\hline Recognised syndromes & $13(0 \cdot 26)$ & $1(0 \cdot 29)$ & $1(0 \cdot 29)$ & $11(73)$ \\
\hline Multiple malformations & $16(0 \cdot 32)$ & $4(1 \cdot 14)^{*}$ & $2(0.59)$ & $14(64)$ \\
\hline Chromosomal & $19(0.38)$ & $2(0.57)$ & 0 & $5(24)$ \\
\hline Total & 151 & 24 & 11 & $110(59)$ \\
\hline
\end{tabular}

Compared with Europeans ${ }^{*} \mathrm{p}<0 \cdot 05,{ }^{* *} \mathrm{p}<0 \cdot 01$. 
defects, renal malformations, and multiple malformations (which were mainly recessive) in the Pakistani population compared with the Europeans, but no significant differences in the incidence of malformations occurring in other systems.

Central nervous system and neural tube defects In 32 of the total of 49 babies in the study with a neural tube defect the diagnosis was made on clinical grounds alone. Three of the babies dying with hydrocephalus had no postmortem examination, destructive procedures having been performed at the time of delivery. In the remaining cases necropsy confirmed the diagnosis. In three cases there had been an affected sibling with a neural tube defect. In one case the mother was an epileptic on phenytoin and phenobarbitone. The incidence of neural tube defects among perinatal deaths in the Pakistani population (2/1000 births) was significantly higher (odds ratio $2.7,95 \%$ confidence interval 1.2 to $6 \cdot 25, \mathrm{p}<0 \cdot 05)$ than among Europeans $(0 \cdot 74 / 1000$ births $)$ or Indians $(0 \cdot 6 / 1000$ births).

\section{Cardiovascular}

In 21 of the 29 cardiac cases the diagnosis was confirmed by postmortem examination. In three cases where necropsy was not performed the diagnosis was based on the results of catheterisation or echocardiography. The remaining five babies had been transferred and died at the receiving hospital and insufficient information was available to establish accurately the nature of the cardiac lesion. In two cases there had been a previous affected sibling with congenital heart disease.

\section{Renal}

Twenty six babies died as a result of renal disorders. The diagnosis was confirmed at necropsy in 20 cases and in the remainder it was made on the basis of the clinical features, antenatal ultrasound findings, or postnatal radiographs and ultrasound. In three cases there was a history of renal malformations in previous siblings. One baby with cystic dysplastic kidneys had a sibling who died in the neonatal period with Potter's syndrome. The histology was reviewed and confirmed cystic dysplasia. One of the babies with prune-belly syndrome was born to a consanguineous couple who already had a child with only one kidney. A consanguineous Pakistani couple had the child with Finnish congenital nephrotic syndrome having had a similarly affected child and another child who was stillborn with cystic dysplastic kidneys. A woman who was an insulin dependent diabetic gave birth to one of the babies with renal agenesis. There was a significantly higher incidence of lethal renal disorders in the Pakistani population compared with the Europeans (odds ratio $4 \cdot 76,95 \%$ confidence interval 1.72 to 12.5 , $\mathrm{p}<0.01)$.

\section{Pulmonary}

The diagnosis was confirmed by necropsy in all cases reported here; there was no relevant family history in any of these babies.

\section{Gastrointestinal}

Postmortem examination had been carried out in all cases. A baby who died with oesophageal atresia was one of twins, the other twin was live born with no abnormalities.

\section{Musculoskeletal}

In all cases the diagnosis had been confirmed by necropsy and, where relevant, the radiographs and histology had been reviewed by experts. Three of the cases of congenital muscular dystrophy occurred $\vec{c}$ in the same European family. The baby with Pena Shokeir syndrome was born to a consanguineous couple with a previously affected child. A woman known to have myotonica dystrophica had the baby who died with congenital myotonic dystrophy.

Recognisable syndromes and multiple malformations There was no difference in the incidence of recognisable syndromes in the different ethnic groups. There was, however, a significantly higher incidence of multiple malformations with no recognisable syndrome in the Pakistani population when compared with the Europeans (odds ratio $3 \cdot 57,95 \%$ confidence interval $1 \cdot 19$ to $11 \cdot 1, \mathrm{p}<0 \cdot 05$ ). In three of the four cases which occurred in Pakistanis these were probably recessive syndromes as there had been a previously affected sibling and these cases occurred in consanguineous couples.

\section{Chromosomal abnormalities}

Abnormal karyotypes were obtained in 16 of the cases described here. A presumptive diagnosis was made in the remaining five cases on the basis of the clinical features (trisomy 13, trisomy 18, two cases of trisomy 21 , and triploidy). There was no difference between ethnic groups in the incidence of abnormal karyotypes.

\section{ANALYSIS OF AUTOSOMAL RECESSIVE CONDITIONS} (TABLE 3)

There were seven perinatal deaths due to autosomal recessive conditions among the European population $(0 \cdot 14 / 1000$ births). Of these, three babies with congenital muscular dystrophy were born to one couple and there were two siblings that died from megacystis megaduodenum. In the Pakistani 
Table 3 Lethal autosomal recessive conditions

\begin{tabular}{lll}
\hline & $\begin{array}{l}\text { Consan- } \\
\text { guinity }\end{array}$ & Race \\
\hline Megacystis megaduodenum $^{8}$ & Yes & European (n=2) \\
Pena Shokeir $^{8}$ & Yes & European \\
Cystic fibrosis $_{\text {Congenital muscular dystrophy }}$ & No & European \\
Congenital muscular dystrophy $^{10}$ & No & European (n=3) \\
Neu-Laxova $^{10}$ & Yes & Pakistani \\
Finnish congenital nephrosis $^{\text {I cell disease }}{ }^{11}$ & Yes & Pakistani \\
Multiple abnormalities & Yes & Pakistani \\
\hline
\end{tabular}

population there were six deaths due to autosomal recessive syndromes. The three multiple abnormalities with no recognisable syndrome occurred in two different but consanguineous couples. One couple had had a previous affected child (delivered outside the study period) with similar clinical features. The other two lethal multiple malformations were stillborn twins born to a couple who had had a previous stillborn child with similar features. The incidence of deaths due to recessive conditions in Pakistanis (1.71/1000 births) was significantly higher than the European rate of $0 \cdot 14 / 1000$ births (odds ratio $12 \cdot 5$, $95 \%$ confidence interval $4 \cdot 17$ to $33 \cdot 3, p<0 \cdot 0001$ ). In the Indian population the rate of $0 \cdot 29 / 1000$ births was not significantly different from the other groups.

\section{CORRECTED PERINATAL MORTALITY RATES}

When corrected for deaths due to autosomal recessive syndromes the Pakistani perinatal mortality rate was $13 \cdot 7 / 1000$ births as compared with $11 \cdot 1 / 1000$ in Europeans (odds ratio $1.25,95 \%$ confidence interval 0.94 to $1.67, p>0.05$ ). The excess deaths were largely due to malformations and were explained by the higher incidence of neural tube defects in the Pakistani population. The perinatal mortality rates per 1000 births corrected for both neural tube defects and autosomal recessive conditions in the different groups were then 10.4 for Europeans, 11.9 for Pakistanis, and 11.9 for Indians. There was no significant difference between the groups. The higher rate of macerated stillbirths in Pakistanis accounted for the remaining excess in perinatal mortality.

\section{POTENTIAL FOR PREVENTION}

Many of these lethal malformations are amenable to detection in the second trimester either by consideration of the family or medical history followed by appropriate investigations or by routine prenatal ultrasound examination. In 11 cases there was a relevant family history and in six of these referral for expert ultrasound examination should have resulted in prenatal detection. In two cases the mother was an insulin dependent diabetic and in one an epileptic on medication and thus they were at increased risk of having a child with a malformation. There was one baby with trisomy 18 whose mother was 38 years old and this would have been detected had she undergone amniocentesis. Review of the remaining lethal malformations shows that a further $59 \%$ could be detected by careful routine prenatal ultrasound performed at 18-20 weeks' gestation (table 2). ${ }^{7}$ In the cases reported here only two cases were detected in the second trimester. One was a neural tube defect where the parents elected to continue with the pregnancy and the other was extrophy of the cloaca in one triplet in an in vitro fertilisation pregnancy. It must be remembered, however, that prenatal ultrasound is considerably more sophisticated now in 1989 than it was in the period of the study.

\section{Discussion}

This study has confirmed the higher perinatal mortality rate and shown the significant contribution of lethal malformations in the Pakistani population as reported by others. ${ }^{2}{ }^{3}$ The pattern of malformations found in the three ethnic groups (table 2) confirms an increase in the number of multiple malformations as described by Terry et al. ${ }^{3} \mathrm{We}$ differ, however, in finding of similar rates of chromosomal abnormalities and, in keeping with Gillies et $a l^{2}$ a significantly higher incidence of neural tube defects in Pakistanis.

Many neural tube defects in this country are now detected by antenatal screening programmes based on routine ultrasound examination in the second trimester or on maternal serum $\alpha$ fetoprotein concentrations. Many women opt for termination of pregnancy when found to have an affected fetus. Lumb et al showed that Asian women tended to book later for their antenatal care with $60.7 \%$ of them booking after 26 weeks. ${ }^{1}$ If this is true of Asian women in other areas it may account for the high contribution of neural tube defects to perinatal mortality as second trimester screening and termination would be available to a relatively smaller proportion of Pakistani women. Furthermore, they may find termination of pregnancy unacceptable on religious grounds. ${ }^{12} \mathrm{We}$ are currently investigating these hypotheses by examining the ultrasound department records of one of our study hospitals where details of prenatal diagnosis of neural tube defects have been kept and by reviewing the maternal case notes of women who had affected babies. 
We have shown the significant contribution of autosomal recessive syndromes to perinatal mortality in the Pakistani population. It is of note that all the autosomal recessive disorders occurring in this group were in babies born to consanguineous couples, as indeed were half of those in the European population. In Bradford, Gillies et al showed that $48 \%$ of Pakistani marriages were between first cousins compared with $8 \%$ of Indian marriages and $0.5 \%$ of non-Asians. ${ }^{2} \mathrm{~A}$ similar pattern has been reported in Birmingham. ${ }^{3}$ In our study we have incomplete ascertainment of consanguinity rates because only one of the four hospitals routinely made direct enquiry of consanguinity. The others only recorded it as a positive finding. Accurate information was also available from those couples who had received genetic counselling. Our findings with regard to consanguinity are shown in table 4, which confirms the trend found in Bradford and Birmingham. These observations indicate that consanguinity has an important influence on the excess perinatal mortality in Pakistanis, but a prospective study with complete ascertainment of consanguinity rates in all ethnic groups is required before this can be proved.

After correction of perinatal mortality rates for autosomal recessive syndromes and neural tube defects there still remains an excess of perinatal deaths in the Pakistani population compared with Europeans. This is largely due to a significantly higher incidence of normally formed macerated stillbirths. As more European $(72 \%)$ than Pakistani $(50 \%)$ perinatal deaths underwent postmortem examination, relatively more internal malformations may have been missed in the latter group. Furthermore the Pakistani population may have been subject to influences such as higher parity, shorter pregnancy interval, and greater maternal age as described by Lumb et al, ${ }^{1}$ and to which a higher perinatal mortality may be attributed. ${ }^{13}$

While this study confirmed the higher perinatal mortality rate in the Pakistani population it failed to show a similar significant trend in Indian Asians as reported by Terry et al. ${ }^{14}$ Explanations for these different observations include differences in both social class and religion between the two Indian populations studied. Most Indians in Birmingham

Table 4 Consanguinity rates (\%)

\begin{tabular}{lccl}
\hline & Consanguineous & $\begin{array}{l}\text { Non- } \\
\text { consanguineous }\end{array}$ & Unknown \\
\hline European & $1 \cdot 2$ & $16 \cdot 9$ & $81 \cdot 9$ \\
Pakistani & $25 \cdot 9$ & $3 \cdot 7$ & $70 \cdot 4$ \\
Indian & 0 & $23 \cdot 3$ & $76 \cdot 7$ \\
\hline
\end{tabular}

are Punjabi Sikhs in social class 4 and $5,{ }^{15}$ whereas in the study reported here they are mainly Hindu and fall into social class 2 and 3 (J Chapple, personal communication). The appreciable differences in cultural and social classification may partly explain the observed discrepancies between the two studies as there is an association between low social class and higher perinatal mortality rates, ${ }^{13}$ and dietary differences may affect maternal nutritional status. ${ }^{16} \vec{\circ}$

What practical steps may taken to reduce the excess risk in the Pakistani population? It seems $\vec{\omega}$ unlikely that structure of society and the incidence of consanguinity will change in the immediate future-indeed a recent study has suggested that there is an increasing rate of consanguineous mar- $\stackrel{\nabla}{\forall}$ riage in Pakistanis in West Yorkshire. ${ }^{17}$ We should therefore direct our attention towards measures such as vitamin supplementation for Asian women both before and during pregnancy as this may help reduce the contribution from neural tube defects. ${ }^{18}-$ Preconceptional and genetic counselling, and expert second trimester ultrasound, should be readily available for all Pakistani women. Their risk of $\ddot{\oplus}$ having a baby die in the perinatal period as a result $\subseteq$ of a congenital malformation is one in 150 , which is higher than the risk level at which screening for Down's syndrome is currently offered on the grounds of maternal age. Those women who have a consanguineous marriage appear to be at greater $\mathbb{D}$ risk. In this study of the 14 perinatal deaths that $\overrightarrow{\vec{F}}$ occurred in consanguineous Pakistani families 10 were due to congenital malformations.

Finally we would urge that full assessment including photography, radiology, cytogenetics, and detailed necropsy of babies who die in the perinatal period should be undertaken to enable accurate diagnosis. This would ensure that parents are fully 3 informed of the risks for future pregnancies and 8 enable the relevant prophylactic and diagnostic facilities to be made available to them.

The authors wish to thank the consultant obstetricians, paediatri- $\frac{7}{0}$ cians, and pathologists, administrative and nursing staff of the hospitals involved for their help and cooperation in the data $\mathrm{N}$ collection and Dr Jean Chapple for her invaluable help, support, $\infty$ and advice. LSC was supported by the Locally Organised Research N Scheme, North West Thames Regional Health Authority.

References

1 Lumb KM, Congdon PJ, Lealman GT. A comparative review of Asian and British-born patients in Bradford, 1974-8. J Epidemiol Community Health 1981;35:106-9.

2 Gillies DRN, Lealman GT, Lumb KM, et al. Analysis of ethnic $\bar{O}$ influence on stillbirths and infant mortality in Bradford 1975-81. J Epidemiol Community Health 1984;38:214-7.

3 Terry PB, Bissenden JG, Condie RG, et al. Ethnic differences in \& congenital malformations. Arch Dis Child 1985;60:866-8. 
4 Young ID, Rickett AB, Clarke M. Genetic analysis of malformations causing perinatal mortality. J Med Genet 1986;23: 58-63.

5 Wigglesworth JS. Monitoring perinatal mortality-a pathophysiological approach. Lancet 1980;ii:684-6.

${ }^{6}$ Morris JA, Gardner MJ. Calculating confidence intervals for relative risks (odds ratios) and standardised ratios and rates. $\mathrm{Br}$ Med J 1988;296:1313-6.

7 Nicolaides KH, Campbell S. Diagnosis and management of fetal malformations. In: Rodeck CR, ed. Clinical obstetrics and gynaecology. London: Baillière Tindall, 1987;1:591-622.

8 Winter RM, Knowles S. Megacystis-microcolon-intestinal hypoperistalsis syndrome: confirmation of autosomal recessive inheritance. J Med Genet 1986;23:360-2.

9 Hall JG. Analysis of Pena Shokeir phenotype. Am J Med Genet 1986;25:99-117.

10 Tolmie JL, Mortimer G, Doyle D, McKenzie R, McLaurin J, Neilson JP. The Neu-Laxova syndrome in female sibs: clinical and pathological features with prenatal diagnosis in the second sib. Am J Med Genet 1987;27:175-82.

1 Smith DW. Leroy I-cell syndrome. Recognisable patterns of human malformation. 3rd ed. Philadelphia: WB Saunders, 1982:332-3.

12 Modell B, Ward RHT, Fairweather DVI. Effect of introducing antenatal diagnosis on reproductive behaviour of families at risk for thalassaemia major. $\mathrm{Br}$ Med $J$ 1980;280:1347-50.

13 OPCS Monitor. Infant and perinatal mortality. London: Office of Population Censuses and Surveys, 1979:1-12.
14 Terry PB, Condie RG, Settatree RS. Analysis of ethnic differences in perinatal statistics. Br Med J 1980;281:1307-8.

15 Settatree RS, Terry PB, Mathew PM, et al. Asian stillbirths in West Birmingham. In: McFadyen IR, MacVicar J, eds. Obstetric problems of the Asian community in Britain. (A scientific meeting of the Royal College of Obstetricians and Gynaecologists 1981.) London: Royal College of Obstetricians and Gynaecologists, 1982:47-55.

16 Haines AP, McFadyen IR, Campbell Brown M, et al. Birthweight and complications of pregnancy in an Asian population. In: McFadyen IR, MacVicar J, eds. Obstetric problems of the Asian community in Britain. (A scientific meeting of the Royal College of Obstetricians and Gynaecologists 1981.) London: Royal College of Obstetricians and Gynaecologists, 1982: 119-26.

17 Darr A, Modell B. The frequency of consanguineous marriage among British Pakistanis. J Med Genet 1988;25:186-90.

18 Seller MJ, Nevin CG. Periconceptual vitamin supplementation and the prevention of neural tube defects in south-east England and Northern Ireland. J Med Genet 1984;21:325-30.

Correspondence to Dr LS Chitty, Department of Paediatric Genetics, Institute of Child Health, 30 Guilford Street, London WC1N 1EH.

Accepted 9 March 1989 